\title{
An Isothermal Steam Expander for an Industrial Steam Supplying System
}

\author{
Chen-Kuang Lin, ${ }^{1}$ Guang-Jer Lai, ${ }^{1}$ Yoshiyuki Kobayashi, ${ }^{2}$ \\ Masahiro Matsuo, ${ }^{3}$ and Min-Chie Chiu ${ }^{4}$ \\ ${ }^{1}$ Department of Mechanical Engineering, Tatung University, 40 Chungshan North Road, 3rd Sector, Taipei, Taiwan \\ ${ }^{2}$ Totigi Central High School, 500 Harihoshi Omitama, Ibaraki Prefecture 319-0133, Japan \\ ${ }^{3}$ Saitama University, 255 Shimookubo, Sakura Ward, Saitama, Saitama Prefecture 338-0825, Japan \\ ${ }^{4}$ Department of Mechanical and Automation Engineering, Chung Chou University of Science and Technology, \\ Changhua County 51003, Taiwan
}

Correspondence should be addressed to Min-Chie Chiu; minchie.chiu@msa.hinet.net

Received 9 September 2014; Accepted 2 December 2014

Academic Editor: Mo Li

Copyright (C) 2015 Chen-Kuang Lin et al. This is an open access article distributed under the Creative Commons Attribution License, which permits unrestricted use, distribution, and reproduction in any medium, provided the original work is properly cited.

\begin{abstract}
Steam is an essential medium used in the industrial process. To ensure steam quality, small and middle scale boilers are often adopted. However, because a higher steam pressure (compared to the necessary steam pressure) is generated, the boiler's steam pressure will be reduced via a pressure regulator before the steam is directed through the process. Unfortunately, pressure is somewhat wasted during the reducing process. Therefore, in order to promote energy efficiency, a pressure regulator is replaced by a steam expander. With this steam expander, the pressure will be transformed into mechanical energy and extracted during the expansion process. A new type of isothermal steam expander for an industrial steam supplying system will be presented in the paper. The isothermal steam expander will improve the energy efficiency of a traditional steam expander by replacing the isentropic process with an isothermal expansion process. With this, steam condensation will decrease, energy will increase, and steam quality will be improved. Moreover, the mathematical model of the isothermal steam expander will be established by using the Schmidt theory, the same principle used to analyze Stirling engines. Consequently, by verifying the correctness of the theoretical model for the isothermal steam expander using experimental data, a prototype of 100 c.c. isothermal steam expander is constructed.
\end{abstract}

\section{Introduction}

Because of the continuing increase in the cost of electricity, reducing manufacturing costs using energy-saving processes is essential. To ensure steam quality, the real pressure is often designated at a higher pressure than its targeted pressure; therefore, the steam is passed through a pressure regulator reducing the pressure before steam is introduced into the system. In this reduction process, energy will be wasted. This drawback can be improved if the pressure regulator is replaced by the steam expander [1-6].

The isothermal expander was inspired by the Rankine Stirling cycle proposed by Isshiki et al. [7]. In that system, steam was guided into the Stirling cycle to improve output efficiency. In 2009, Yoshiyuki [8] developed an $\alpha$ type steam
Stirling engine with a higher output efficiency [9]. In line with the design concept of the Rankine Stirling cycle and an $\alpha$ type steam Stirling engine, a new type of isothermal steam expander used to increase output work is proposed in this paper. Here, an isentropic process is replaced by the isothermal expansion process. The isothermal steam expander can reduce steam condensation, increase output efficiency, and improve steam quality. In order to enhance the isothermal expansion process, the heat regenerator for the traditional steam expander is improved. Also, based on the Schmidt theory, the theoretical $P-V$ diagram and related output efficiency will be established. Consequently, a prototype 100 c.c. isothermal steam expander is built and used to verify the correctness of the mathematical model. 

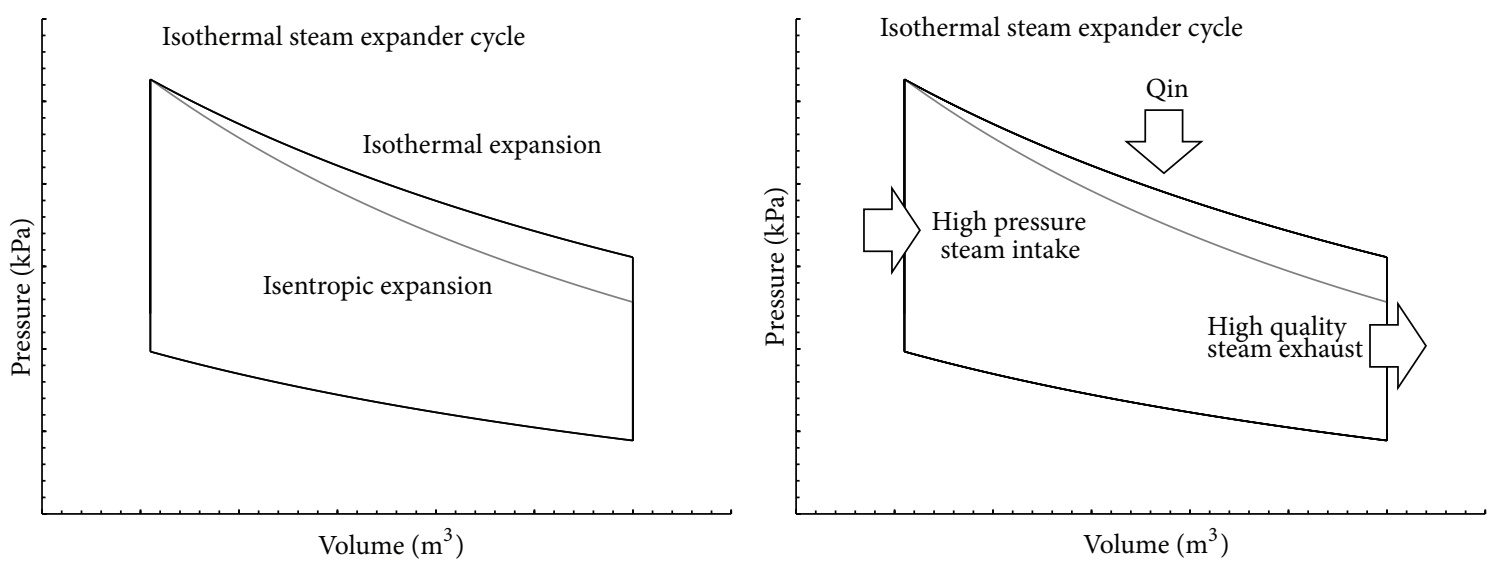

FIGURE 1: The ideal isothermal expansion cycle for a steam expander.

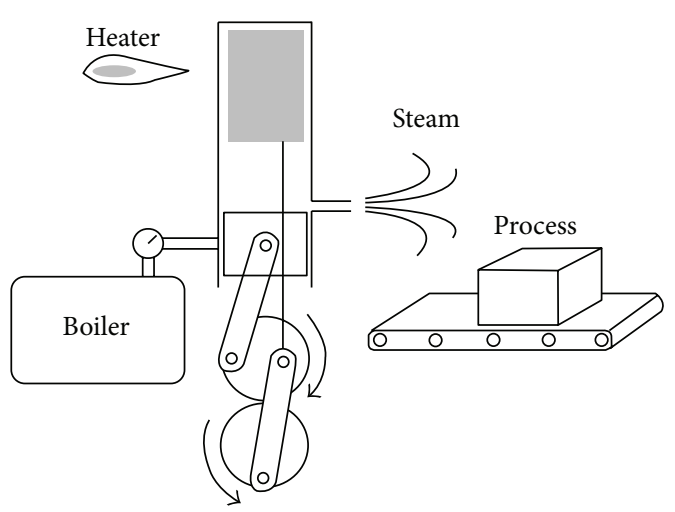

FIgURE 2: The isothermal steam expander.

\section{Design Concept of the Isothermal Steam Expander}

A cogeneration system is very efficient for energy transformation. Current cogeneration systems are often linked to large scale steam turbines. However, the development of a small scale steam supplying system used in the cogeneration system is rare. In order to develop cogeneration systems that extract more output work from the steam's pressure, research on a small scale cogeneration system linked with a small boiler and a steam expander becomes crucial. In this study, the traditional steam expander is improved. In order to decrease the steam's condensation, the isentropic process is replaced by an isothermal expansion process using a thermal expansion type steam expander.

As indicated in Figure 1, the isothermal expansion cycle of the steam expander is composed of two isothermal processes and two isovolumetric processes. High pressure steam will be guided into the isothermal expansion cycle of the steam expander. The cycle will produce heat and then do mechanical work. Subsequently, steam will be discharged and introduced into the manufacturing process. The steam pressure will then be decreased and extra heat will be produced. The resulting

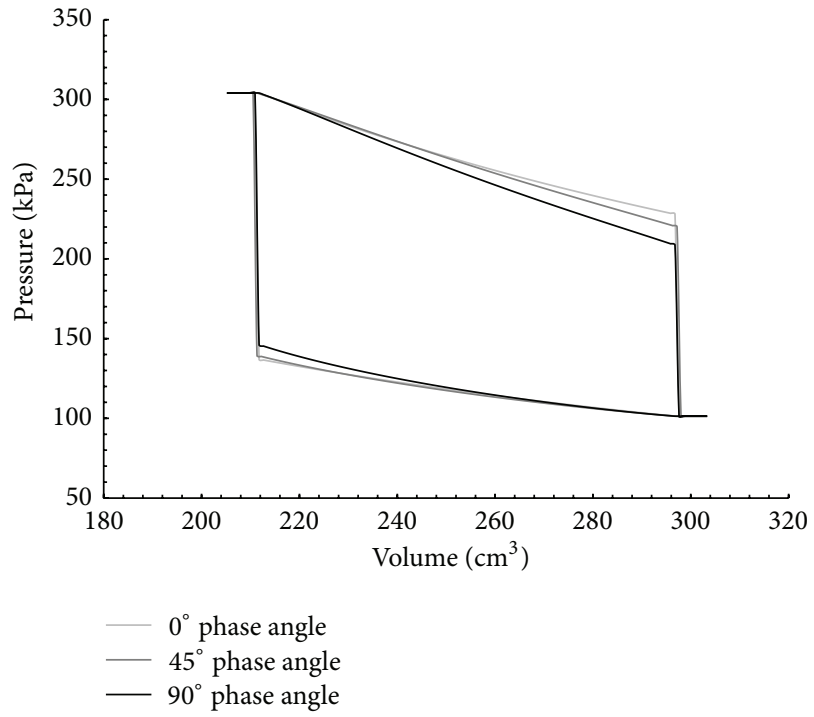

FIGURE 3: The influence of the $P-V$ diagram with respect to various phase angles.

quality of the steam released from the isothermal expansion cycle will be improved. Moreover, the output efficiency produced by the isothermal expansion cycle is increased beyond that of the traditional expander.

As indicated in Figure 2, the isothermal steam expander is similar to the $\beta$ type Stirling cycle. The phase angle between the piston and the regenerator (displacer) is set at $90^{\circ}$. Because the intake valve and the exhaust valve are set in the isothermal steam expander, high pressure gas will be introduced into the cycle when the piston approaches top dead center. Additionally, low pressure gas will be discharged when the piston approaches bottom dead center. However, the $90^{\circ}$ phase angle is not the best value for producing more mechanical work. Therefore, based on the Schmidt theory, an analysis of the best phase angle for the isothermal steam expander is assessed in the following section. 


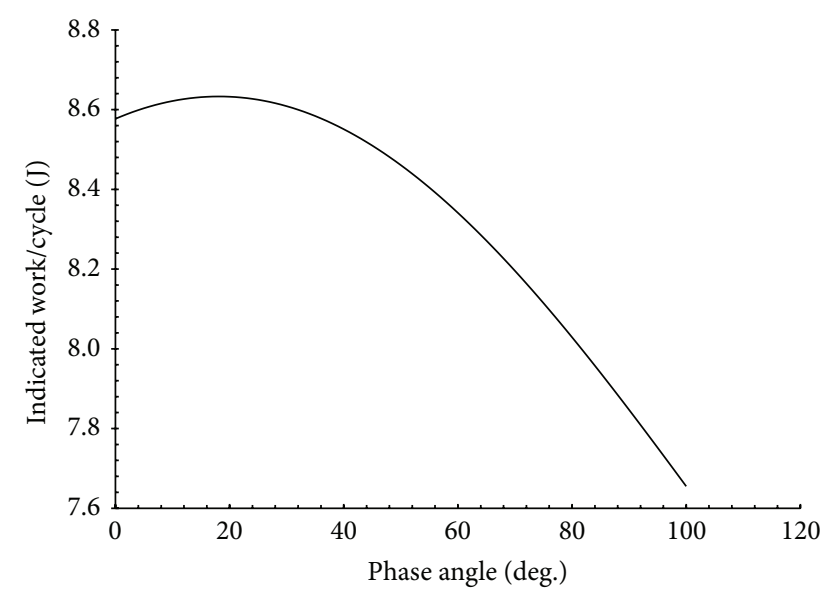

FIGURE 4: Output work with respect to the phase angle (between the piston and the displacer of the isothermal expander).

\section{Mathematical Model of the Isothermal Steam Expander}

The isothermal expander is similar to the $\beta$ type Stirling engine cycle. Based on the Schmidt theory $[10,11]$, the relationship in the $P-V$ diagram between the instant pressure and the volume inside the isothermal expander will be predicted and plotted. Also, based on the $\beta$ type Stirling cycle's Schmidt theory, the relationship between the instant pressure and the axial output phase angle can be predicted. The related temperature ratio for the hot end and the cold end, the stroke volume ratio, and the dead space ratio are

$$
\begin{gathered}
\tau=\frac{V_{c}}{V_{h}}, \\
\kappa=\frac{V_{s p}}{V_{s d}}, \\
X=\frac{V_{d h}+V_{r}+V_{d c}}{V_{h}}
\end{gathered}
$$

assuming that

$$
\begin{gathered}
\psi=\tan ^{-1} \frac{\kappa \sin \alpha}{\tau+\kappa \cos \alpha+1}, \\
X_{B}=\frac{V_{b}}{V_{s d}}, \\
S=\tau+\frac{4 \tau X}{1+\tau}+\tau+1-2 X_{B}, \\
B=\sqrt{\tau^{2}+2 \kappa(\tau+1) \cos \alpha+\kappa^{2}+2 \tau+1}, \\
\delta=\frac{B}{S} .
\end{gathered}
$$

According to the Schmidt theory, the relationship between the instant pressure and the output phase angle is

$$
P=\frac{P_{\text {mean }} \sqrt{1-\delta^{2}}}{1-\delta \cdot \cos (\theta-\phi)} .
$$

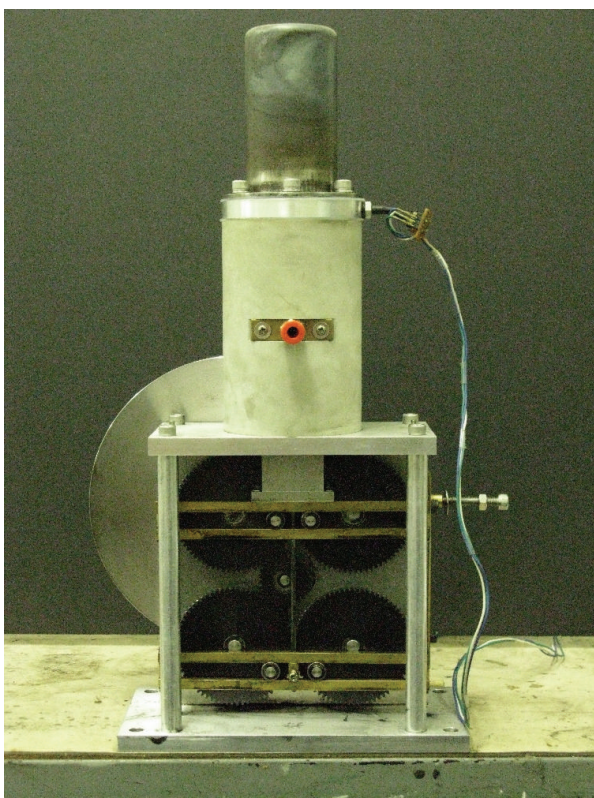

FIGURE 5: The prototype of the isothermal expander with a capacity of 100 c.c.

For the isothermal expander, the instant pressure will be the same as $P_{h}$ (the pressure of the pressure source) when the valve opens. The average effective $P_{\text {mean-e }}$ can be obtained by including the $\theta_{h v c}$ and $P_{h}$ (occurring at the valve closing) in the calculation. Here, $P$ will be the same as $P_{h}$ at $\theta_{h v_{o}}>\theta>$ $\theta_{h v c}$. The instant pressure during the expansion process is

$$
\begin{gathered}
P_{e}=\frac{P_{\text {mean }-e} \sqrt{1-\delta^{2}}}{1-\delta \cdot \cos (\theta-\psi)} \quad\left(\text { where } \theta_{h v c}>(\theta-\alpha)>\theta_{l v o}\right), \\
P_{h}=\frac{P_{\text {mean }-e} \sqrt{1-\delta^{2}}}{1-\delta \cdot \cos \left(\theta_{h v c}-\psi\right)}, \\
P_{\text {mean-e }}=\frac{P_{h}\left(1-\delta \cdot \cos \left(\theta_{h v c}-\psi\right)\right)}{\sqrt{1-\delta^{2}}}, \\
P_{e}=\frac{P_{h}\left(1-\delta \cdot \cos \left(\theta_{h v c}-\psi\right)\right)}{1-\delta \cdot \cos (\theta-\psi)} \\
\left(\text { where } \theta_{h v c}>(\theta-\alpha)>\theta_{l v o}\right) .
\end{gathered}
$$

Similarly, the instant pressure of the isothermal compression process is

$$
P_{c}=\frac{P_{l}\left(1-\delta \cdot \cos \left(\theta_{l v c}-\psi\right)\right)}{1-\delta \cdot \cos (\theta-\psi)}
$$$$
\text { (where } \left.\theta_{l v c}>(\theta-\alpha)>\theta_{h v o}\right) \text {. }
$$

Because the instant pressure will be the same as $P_{h}$ (the pressure of the pressure source) when the valve opens, 

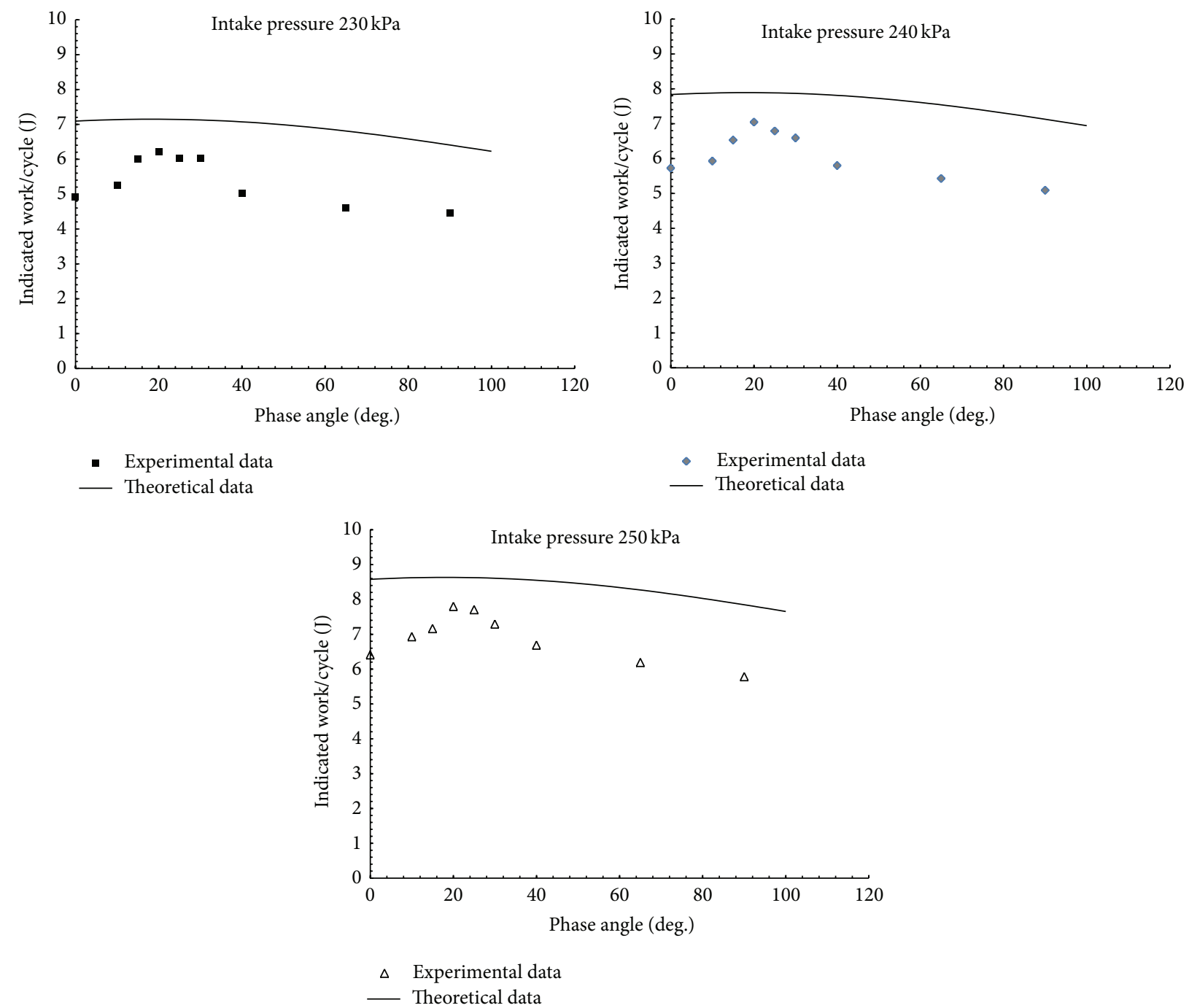

Figure 6: The comparison at various intake pressure conditions between the theoretical output work and the experimental data.

the relationship between the instant pressure and the axial output's phase angle for the isothermal expander is

$$
\begin{gathered}
P=P_{e}=\frac{P_{h}\left(1-\delta \cdot \cos \left(\theta_{h v c}-\psi\right)\right)}{1-\delta \cdot \cos (\theta-\psi)} \\
\left(\text { where } \theta_{l v c}>(\theta-\alpha)>\theta_{l v o}\right), \\
P=P_{c}=\frac{P_{l}\left(1-\delta \cdot \cos \left(\theta_{l v c}-\psi\right)\right)}{1-\delta \cdot \cos (\theta-\psi)} \\
\quad\left(\text { where } \theta_{l v c}>(\theta-\alpha)>\theta_{h v o}\right), \\
P=P_{h} \quad\left(\text { where } \theta_{h v o}>(\theta-\alpha)>\theta_{h v c}\right), \\
P=P_{l} \quad\left(\text { where } \theta_{l v o}>(\theta-\alpha)>\theta_{l v c}\right) .
\end{gathered}
$$

Inputting the design parameters and the related operating conditions of the 100 c.c. isothermal expander into the above equations, the resulting $P-V$ diagram is plotted and shown in Figure 3. Figure 3 indicates that the black line profile is the $90^{\circ}$ phase angle. The deep gray line represents the $45^{\circ}$ phase angle. Finally, the shallow gray line is the $0^{\circ}$ phase angle.

The output work with respect to the phase angle is depicted in Figure 4. As indicated in Figure 4, the maximal output work will occur when the phase angle is $19.6^{\circ}$.

\section{Experimental Work of the Isothermal Steam Expander}

In order to verify the correctness of the mathematical model of the isothermal expander, a prototype of the 100 c.c. isothermal expansion expander is constructed and shown in Figure 5. The surface of the piston and the cylinder is coated with a thin ceramic film. The hot end is made of stainless steel. The total height of the cylinder is $410 \mathrm{~mm}$ and the diameter is $50 \mathrm{~mm}$. The piston stroke and the displacer are $50 \mathrm{~mm}$. The venting rate per stroke is 98.2 c.c. In order to conveniently operate and adjust the isothermal expander, the piston is linked to the displacer with a gear. The related phase angle is adjustable. 


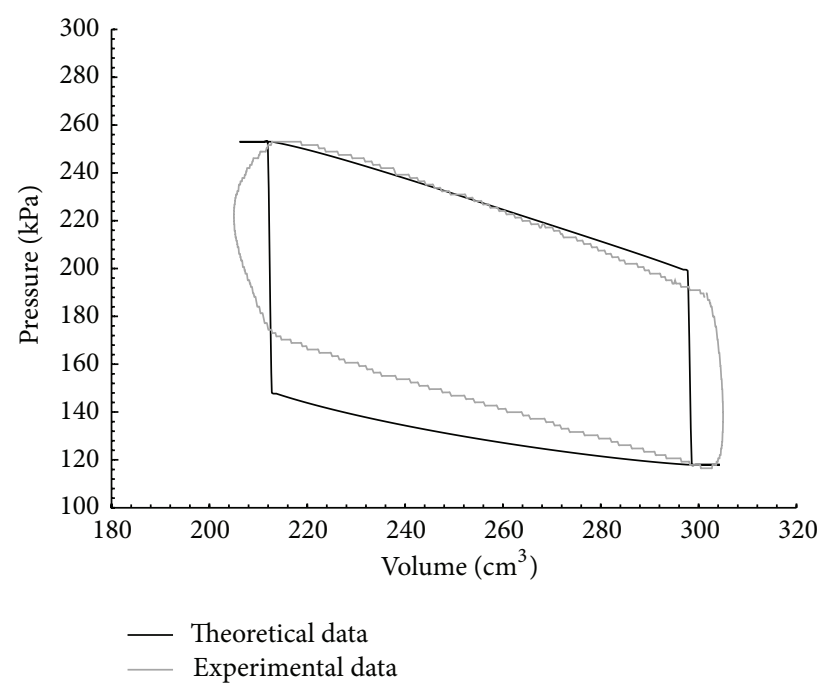

Figure 7: The comparison of theoretical $P-V$ diagram with the experimental data at the same intake pressure.

In order to acknowledge the relationship between the mechanical output work and the phase angle, the internal instant pressure of the isothermal expander is detected by a pressure sensor IC at various phase angles. The $P-V$ diagram is then obtained. Furthermore, the area of the $P-V$ diagram which shows mechanical output work will be calculated.

\section{Results and Discussion}

In the experimental work, the high pressure steam of the intake pressure source will be replaced by compressed air $[12,13]$. The intake pressure will be set at $450 \mathrm{kPa}, 400 \mathrm{kPa}$, and $350 \mathrm{kPa}$. Because of the retarding force, the air pressure will decrease when the air flows through the channel. The real intake air pressures become $250 \mathrm{kPa}, 240 \mathrm{kPa}$, and $230 \mathrm{kPa}$. Inputting the data into the formula, we have found that a $19.6^{\circ}$ phase angle will produce a maximal output of work. Because the hardware's resolution of the phase angle is $1^{\circ}$, the setting of the phase angle is $15^{\circ}, 20^{\circ}, 25^{\circ}, 30^{\circ}, 40^{\circ}, 65^{\circ}$, and $90^{\circ}$. The related output work can also be measured. Consequently, a comparison at various intake pressure conditions between the theoretical output work and the experimental data is shown in Figure 6. As indicated in Figure 6, the black line represents the theoretical profile of the output work with respect to the phase angle. Figure 6 indicates that the maximal output work will occur when the phase angle is $20^{\circ}$. The output work will decrease when the phase angle is increased or decreased from $20^{\circ}$. Here, it is understood that the output work will be at a minimum when the phase angle is $90^{\circ}$. As indicated in Figure 7 , the black line represents the theoretical $P-V$ diagram. The gray line represents the experimental data. It is obvious that the theoretical $P-V$ diagram is similar to that of the experimental data.

In the experimental work, because of the insufficient cooling rate of the working fluid during the isothermal compression process, the real temperature of the gas will be greater than what the theoretical data shows. Therefore, a rapid pressure increase will occur resulting in output work appearing in a small area of the experimental $P-V$ diagram. This is why the theoretical area of the $P-V$ diagram is greater than the experimental diagram.

\section{Conclusion}

To improve the output efficiency of the expander, an isothermal steam expander is proposed. The isothermal expander will be similar to the $\beta$ type Stirling engine. Because the high pressure gas intake and gas discharge are added inside the isothermal expander, the setting of the phase angle between the piston and the displacer needs to be appropriately adjusted.

The intent of this paper has been to provide a mathematical model of an isothermal expander using a modified Schmidt theory. Additionally, a prototype of 100 c.c. isothermal expander was constructed and used to verify the correctness of the isothermal expander's mathematical model. Results reveal that the theoretical $P-V$ diagram is similar to that of the experimental data. As can be seen, the maximal theoretical output work of the 100 c.c. isothermal expander will occur at the phase angle of $19.6^{\circ}$. Additionally, the maximal experimental output work occurs when the phase angle is at $20^{\circ}$. Consequently, the approach used for the optimal phase angle of the isothermal steam expander of various sizes proposed in this study efficiently produces maximal output work.

\section{Nomenclature}

$m: \quad$ Mass of working fluid $(\mathrm{kg})$

$P: \quad$ Instant pressure of inner space $(\mathrm{kPa})$

$P_{\text {mean }}:$ Average pressure $(\mathrm{kPa})$

$P_{\text {mean-e }}$ : Average pressure of expansion process $(\mathrm{kPa})$

$P_{\text {mean-c }}:$ Average pressure compression process $(\mathrm{kPa})$

$P_{e}: \quad$ Instant pressure of expansion cycle $(\mathrm{kPa})$

$P_{c}$ : Instant pressure of compression cycle $(\mathrm{kPa})$

$P_{h}: \quad$ Pressure of intake fluid $(\mathrm{kPa})$

$P_{l}$ : $\quad$ Pressure of exhaust fluid $(\mathrm{kPa})$

R: $\quad$ Gas constant $(\mathrm{kJ} / \mathrm{kg} \mathrm{K})$

$T_{c}$ : $\quad$ Temperature of cold end (K)

$T_{h}$ : Temperature of hot end $(\mathrm{K})$

$T_{r}: \quad$ Temperature of regenerator $(\mathrm{K})$

$V: \quad$ Instant volume of inner space $\left(\mathrm{m}^{3}\right)$

$V_{b}$ : Overlap volume of piston and displacer $\left(\mathrm{m}^{3}\right)$

$V_{c}: \quad$ Instant volume of cold space $\left(\mathrm{m}^{3}\right)$

$V_{d}: \quad$ Volume of dead space $\left(\mathrm{m}^{3}\right)$

$V_{d c}$ : Volume of dead space in cold end $\left(\mathrm{m}^{3}\right)$

$V_{d h}: \quad$ Volume of dead space in hot end $\left(\mathrm{m}^{3}\right)$

$V_{d p}: \quad$ Volume of dead space in piston $\left(\mathrm{m}^{3}\right)$

$V_{d r}: \quad$ Volume of dead space in regenerator $\left(\mathrm{m}^{3}\right)$

$V_{h}$ : Instant volume of hot space $\left(\mathrm{m}^{3}\right)$

$V_{s d}$ : Swept volume of displacer $\left(\mathrm{m}^{3}\right)$ 
$V_{s p}:$ Swept volume of piston $\left(\mathrm{m}^{3}\right)$

$W: \quad$ Mechanical work $(\mathrm{kJ})$

$\theta$ : Shaft angle where displacer at TDC is $0^{\circ}\left({ }^{\circ}\right)$

$\theta_{h v c}:$ Intake valve closing angle $\left(^{\circ}\right)$

$\theta_{l v c}$ : Exhaust valve closing angle $\left(^{\circ}\right)$

$\theta_{h v o}$ : Intake valve opening angle $\left({ }^{\circ}\right)$

$\theta_{l v_{0}}$ : Exhaust valve opening angle $\left(^{\circ}\right)$

$\alpha$ : $\quad$ Phase angle between the piston shaft and displacer shaft $\left({ }^{\circ}\right)$.

\section{Conflict of Interests}

The authors declare that there is no conflict of interests regarding the publication of this paper.

\section{References}

[1] O. Badr, S. Naik, P. W. O’Callaghan, and S. D. Probert, "Wankel engines as steam expanders: design considerations," Applied Energy, vol. 40, no. 3, pp. 157-170, 1991.

[2] Y. Kawabata, K. Okumoto, H. Takahashi et al., "Study on heat recovery generation system for Co-generation (2nd report, fundamental analysis on performance characteristics of scroll steam expander)," Transactions of the Japan Society of Mechanical Engineers, Part B, vol. 73, no. 11, pp. 2317-2322, 2007.

[3] I. Shogo, K. Naoki, I. Soichiro et al., "Study on heat recovery generation system for co-generation: 3 rd report, improvement in efficiency of scroll steam expander (thermal engineering)," Transactions of the Japan Society of Mechanical Engineers, vol. 76, no. 765, pp. 845-851, 2010.

[4] R. Cipollone, G. Contaldi, G. Bianchi, and S. Murgia, "Energy recovery using sliding vane rotary expanders," in Proceedings of the 8th International Conference on Compressors and Their Systems, pp. 183-194, September 2013.

[5] C. Champagne and L. Weiss, "Performance analysis of a miniature free piston expander for waste heat energy harvesting," Energy Conversion and Management, vol. 76, pp. 883-892, 2013.

[6] I. K. Smith, N. Stosic, and A. Kovacevic, Power Recovery from Low Grade Heat by Means of Screw Expanders, Chandos Publishing, 2014.

[7] N. Isshiki, H. Kojima, I. Ushiyama, and S. Isshiki, "Proposal and basic experiments of super stirling engines," SAE Technical Paper 1999-01-2502, 1999.

[8] K. Yoshiyuki, "Model steam rankine Stirling engine foreducational use," in Proceedings of the 2009 Symposium on Stirlling Cycle, vol. 12, pp. 83-84, November 2009.

[9] O. N. Igobo and P. A. Davies, "Review of low-temperature vapour power cycle engines withquasi-isothermal expansion," Energy, vol. 70, pp. 22-34, 2014.

[10] G. Walker, Stirling Engines, Oxford University Press, 1980.

[11] D. G. Thombare and S. K. Verma, "Technological development in the Stirling cycle engines," Renewable \& Sustainable Energy Reviews, vol. 12, no. 1, pp. 1-38, 2008.

[12] L. Guangbin, Z. Yuanyang, L. Liansheng, and S. Pengcheng, "Simulation and experiment research on wide ranging working process of scroll expander driven by compressed air," Applied Thermal Engineering, vol. 30, no. 14-15, pp. 2073-2079, 2010.

[13] W. He, Y. Wu, Y. Peng, Y. Zhang, C. Ma, and G. Ma, "Influence of intake pressure on the performance of single screw expander working with compressed air," Applied Thermal Engineering, vol. 51, no. 1-2, pp. 662-669, 2013. 


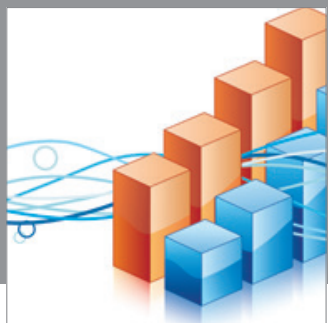

Advances in

Operations Research

mansans

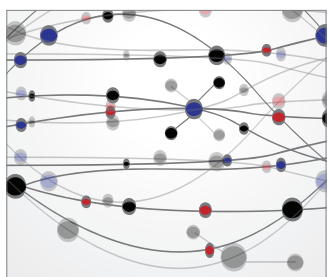

The Scientific World Journal
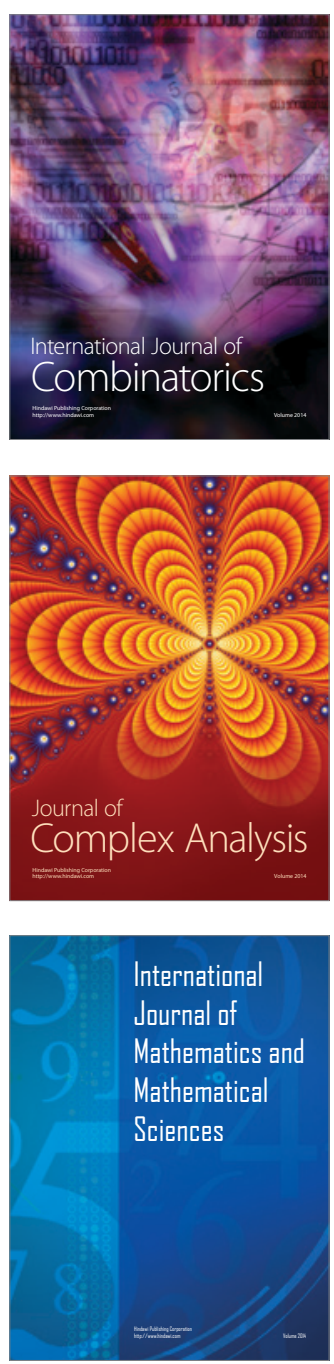
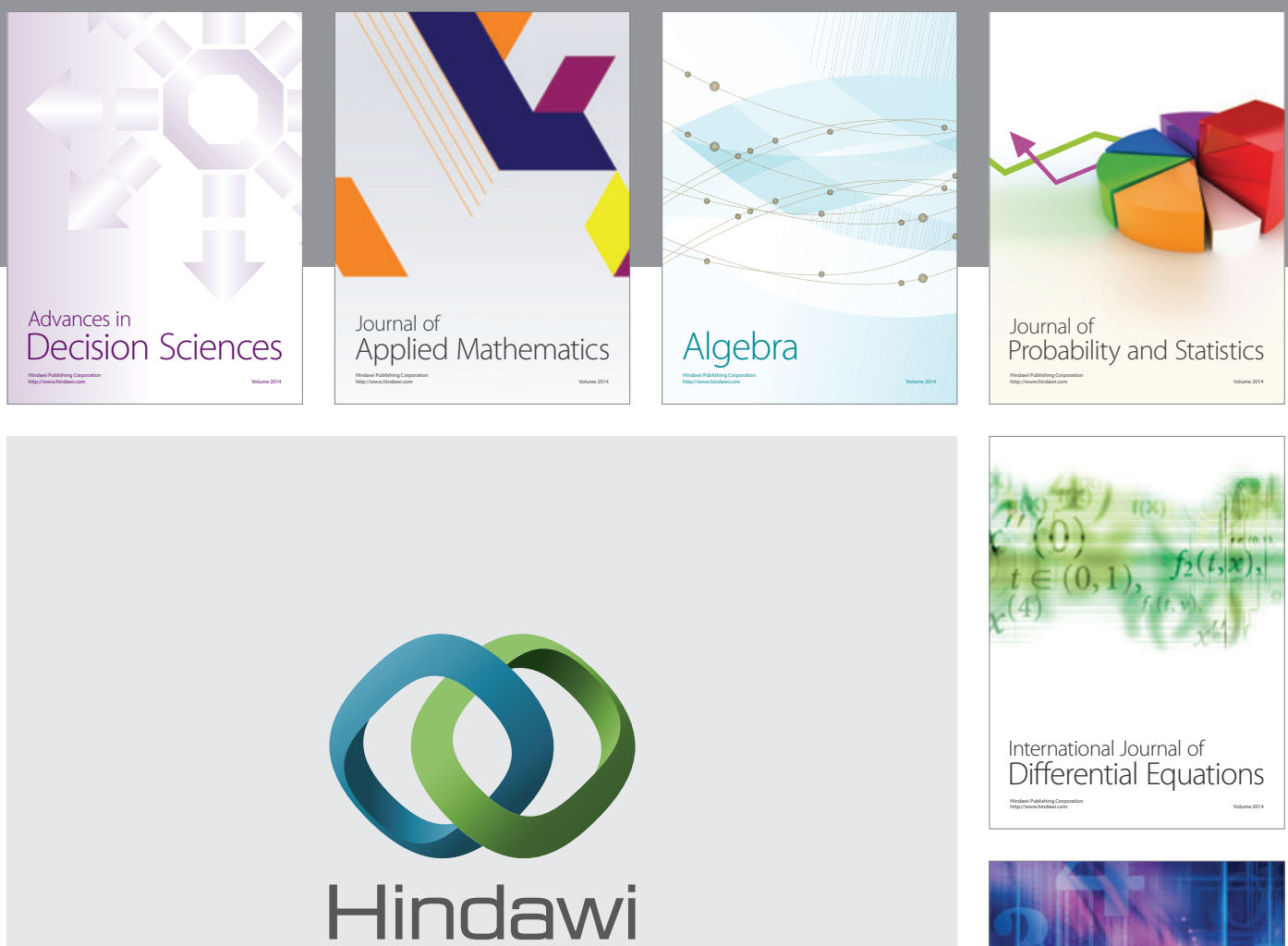

Submit your manuscripts at http://www.hindawi.com
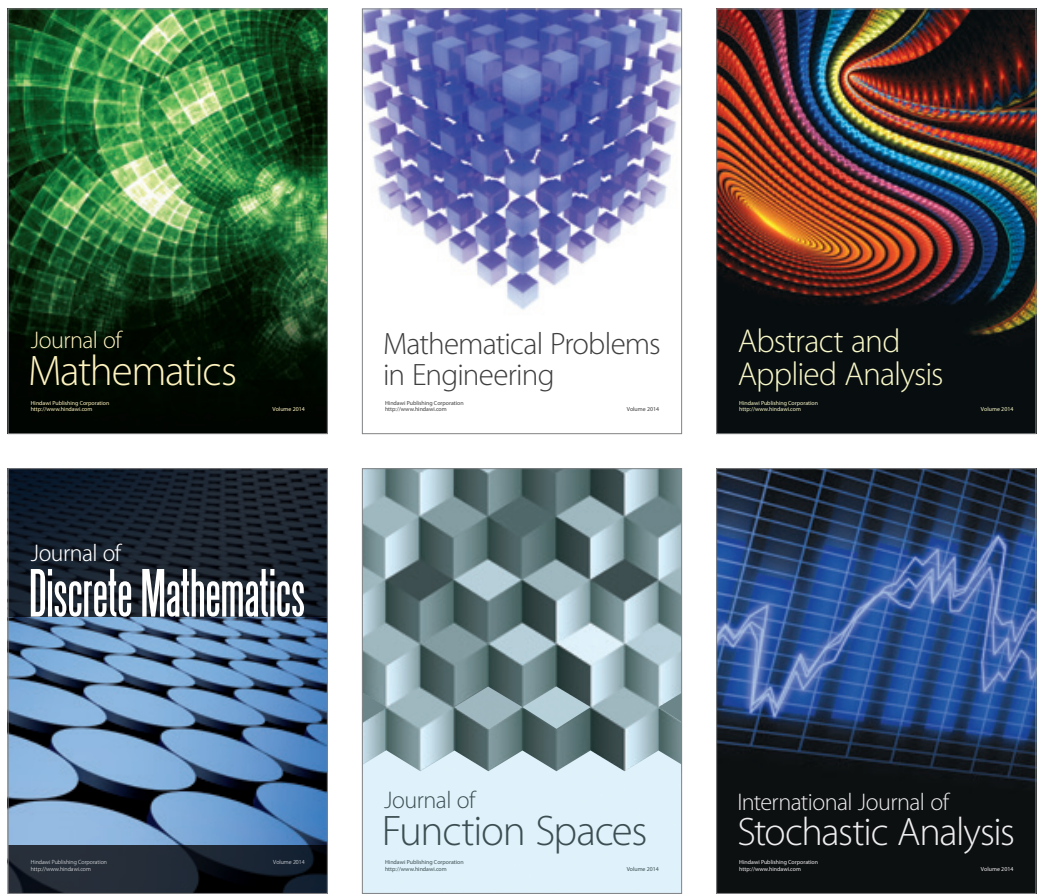

Journal of

Function Spaces

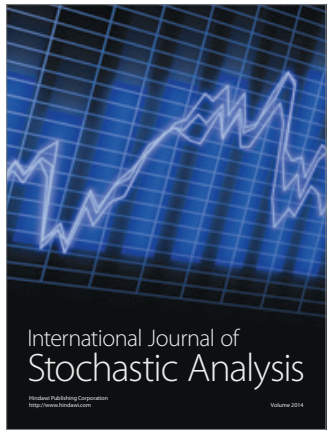

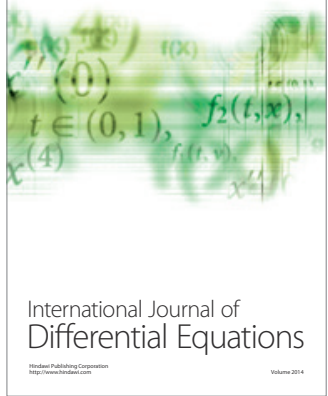
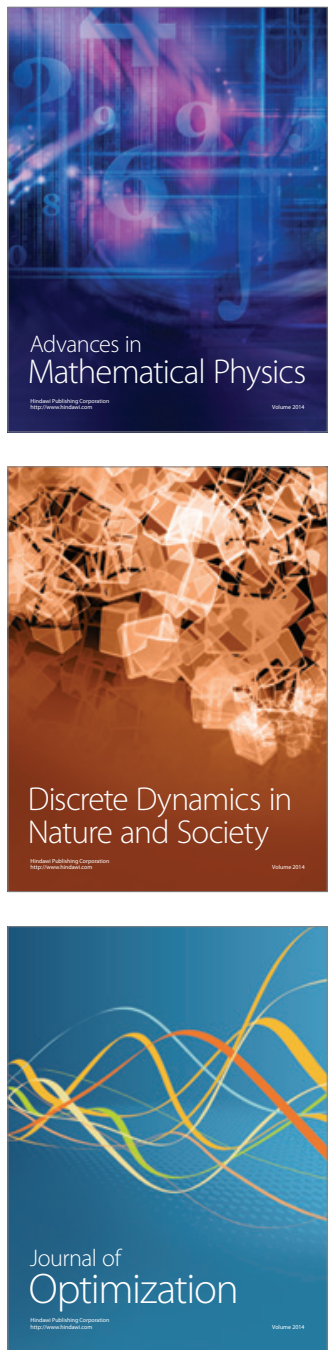